\title{
Feds, Manitoba lifting some pandemic restrictions based on vaccine status
}

\author{
Cite as: CMAJ 2021 July 5;193:E1016. doi: 10.1503/cmaj.1095948
}

Posted on cmajnews.com on June 9, 2021

$\mathrm{T}$ he federal government said on June 9 it is aiming to lift some pandemic travel restrictions for Canadians who are fully vaccinated against COVID-19, starting as early as July.

Depending on vaccination rates and trends in new infections, Canadians who are fully vaccinated will no longer need to self-isolate for 14 days or stay in quarantine hotels when they return from travel abroad.

The government will consider people to be fully vaccinated if they have completed a full course of the Pfizer, Moderna, AstraZeneca or Johnson \& Johnson COVID-19 vaccines at least 14 days before arrival in Canada. It's not clear what specific documentation the federal government will accept as proof of vaccination or how this applies to people who received different vaccine products for their first and second shots.

Fully vaccinated foreign travellers will still have to show a negative test for COVID-19 before boarding flights to Canada, and take another test upon arrival and selfisolate until the results come back negative.

Meanwhile, Manitoba's government announced it would allow people who are fully vaccinated to travel within Canada without having to quarantine when they return to the province. Unvaccinated children under age 12 who are travelling with fully vaccinated adults will be exempt from quarantine requirements, too.

Fully vaccinated Manitobans will also face fewer restrictions on visiting loved ones in hospitals and care homes, and will not have to isolate if they are in close contact with someone who tests positive for COVID-19.

The province will issue digital and paper vaccine cards with a person's

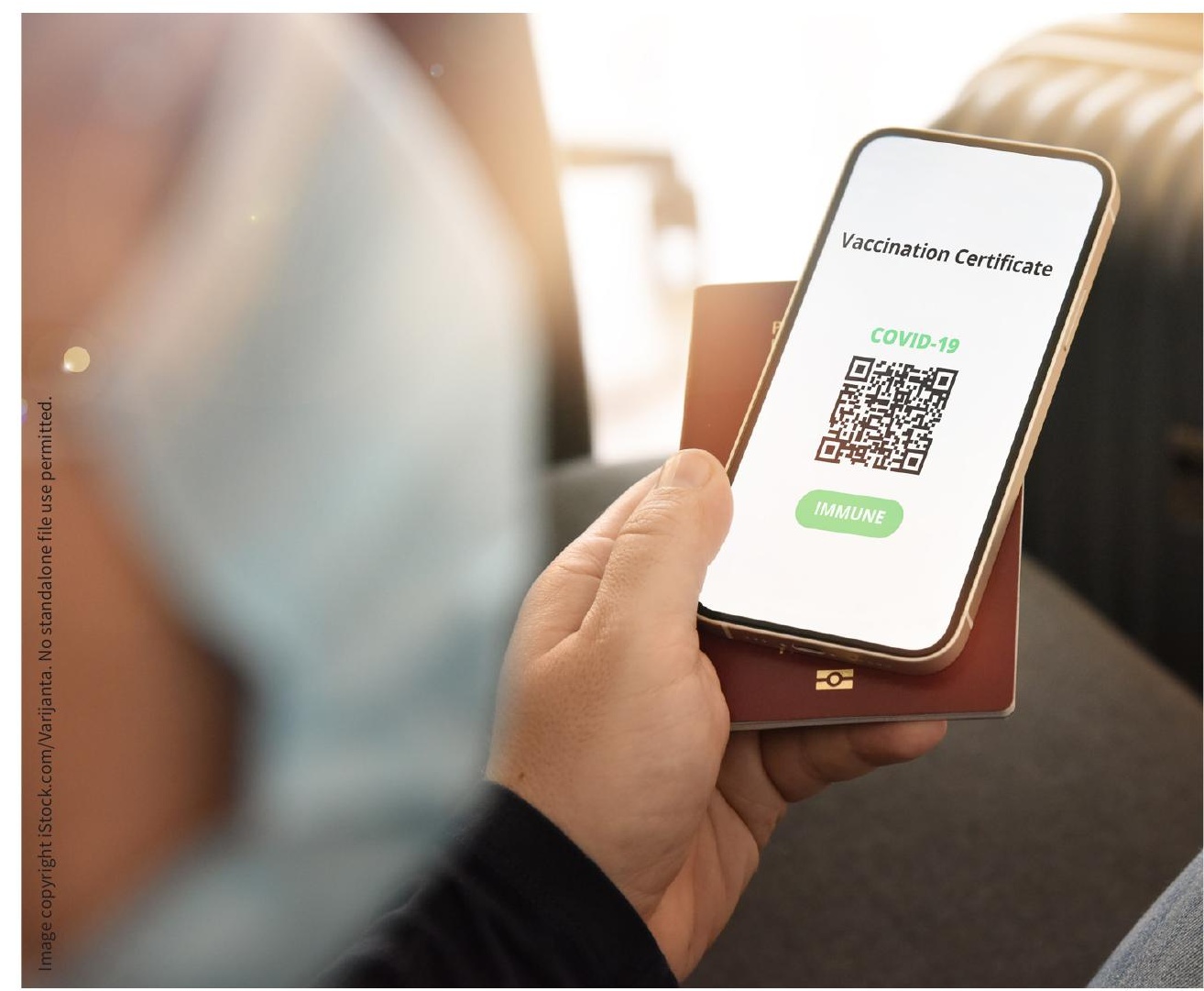

The federal government and Manitoba will ease travel restrictions for people fully vaccinated against COVID-19.

name and a QR code that can be scanned to confirm their vaccination status. No other personal information will be listed on the card.

According to Manitoba officials, the policy is intended to encourage vaccination among people who are hesitant, and they may ease more pandemic restrictions for people who are vaccinated as the province reopens. Quebec officials said they are considering similar policies.

As yet, it's unclear whether Manitoba will provide any special accommodations or appeal mechanisms for people who are unable or unwilling to be vaccinated.

\section{Lauren Vogel, CMAJ}

Content licence: This is an Open Access article distributed in accordance with the terms of the Creative Commons Attribution (CC BY-NC-ND 4.0) licence, which permits use, distribution and reproduction in any medium, provided that the original publication is properly cited, the use is noncommercial (i.e., research or educational use), and no modifications or adaptations are made. See: https://creativecommons. org/licenses/by-nc-nd/4.0/ 